\title{
EDUCAÇÃO DE JOVENS E ADULTOS EM CONTEXTO PANDÊMICO: entre o remoto e a invisibilidade nas políticas curriculares
}

\author{
Alessandra Nicodemos \\ Universidade Federal do Rio de Janeiro - UFRJ \\ Enio Serra \\ Universidade Federal do Rio de Janeiro - UFRJ
}

\begin{abstract}
Resumo
A partir dos desafios postos à Educação de Jovens e Adultos (EJA) pela pandemia da covid-19, o artigo traz como problema a ser analisado os efeitos da crise sanitária na vida dos trabalhadores que cursam a Educação Básica e suas repercussões nas políticas curriculares dirigidas a essa modalidade de ensino. Seus propósitos giram em torno da reflexão acerca da dimensão e da abrangência desses impactos, principalmente no que se refere aos discursos que balizam as decisões educacionais relativas às atividades remotas e às políticas curriculares tanto no contexto pandêmico quanto no período pós-pandemia. Como base metodológica, o estudo mobiliza dados relativos à pandemia e à educação nesse contexto disponibilizados por universidades, institutos de pesquisa e órgãos educacionais, assim como a legislação pós-2016 responsável por importantes consequências para a EJA. As conclusões expostas alertam para a complexidade e gravidade da atual conjuntura ao presumir possíveis ameaças à EJA em seu projeto de garantia do direito à educação socialmente referenciada para jovens, adultos e idosos das classes populares.
\end{abstract}

Palavras-chave: Educação de Jovens e Adultos, Ensino Remoto, Políticas de Currículo, Pandemia da Covid-19.

\begin{abstract}
Based on the challenges posed to Youth and Adult Education (EJA) by the covid-19 pandemic, the article brings the effects of the health crisis on the lives of workers in Basic Education and its repercussions on curricular policies directed to this type of teaching as problems to be analyzed. Its purposes revolve around reflecting on the dimension and scope of these impacts, especially regarding the discourses that guide educational decisions concerning remote activities and curricular policies both in the pandemic context and in the post-pandemic period. As a methodological basis, the study mobilizes data related to the pandemic and education in this context provided by universities, research institutes and educational bodies, as well as the post-2016 legislation responsible for important consequences for EJA. The conclusions exposed warn of the complexity and seriousness of the current situation by assuming possible threats to EJA in its project of guaranteeing the right to socially referenced education for youth, adults and the elderly of the popular classes.
\end{abstract}

Keywords: Youth and Adult Education, Remote Teaching, Curriculum Policies, Covid-19 Pandemic.

ISSN 1645-1384 (online) www.curriculosemfronteiras.org

http://dx.doi.org/10.35786/1645-1384.v20.n3.14 


\section{Introdução}

A luta pela garantia de direitos sociais e humanos em uma sociedade historicamente marcada por desigualdades e pelo não reconhecimento das diferenças não é novidade no Brasil. Entre tantos enfrentamentos, a luta pela educação como direito de todos vem sendo conquistada a passos lentos e uma de suas dimensões mais dramáticas consiste na busca pela conclusão da Educação Básica por jovens, adultos e idosos. Em um país onde 51,2\% da população com 25 anos ou mais não tinham assegurado esse direito, em 2019 (IBGE, 2020b), outros direitos negados somam-se e formam um conjunto de violações que atingem, sobremaneira, um contingente bastante considerável de indivíduos. Em 2020, a esses tantos embates históricos acrescenta-se um dos mais agudos nos últimos 100 anos: a luta pela sobrevivência em meio à disseminação do novo coronavírus e à pandemia da covid-19.

Como meio de acesso à escolarização tardia, a Educação de Jovens e Adultos (EJA) vem se conformando em uma modalidade de ensino definida por avanços e recuos em suas pautas reivindicatórias e, ainda hoje, marcha pela garantia plena de sua oferta pelo poder público. Esse quadro deve-se ao que Arroyo (2005) já alertava, há algum tempo: o caráter marginalizado da EJA nas políticas educacionais é explicado pelas características sociais, econômicas e culturais de seu público. Para o autor, a "história oficial da EJA se confunde com a história do lugar social reservado aos setores populares. É uma modalidade do trato dado pelas elites aos adultos populares" (ARROYO, 2005, p. 221). Concordando com essa análise, consideramos que o contexto da pandemia não só mostrou sua pertinência, como também revelou o aprofundamento do descaso das elites econômicas e políticas com os trabalhadores, principalmente aqueles mais pauperizados. E à invisibilidade de muitos desses sujeitos nas políticas implementadas para o combate à disseminação da covid-19, somou-se a invisibilidade da EJA nas políticas educacionais durante o período de distanciamento social.

Instituído esse quadro, muitas e diferentes questões surgiram e passaram a fazer parte de debates entre profissionais da educação, gestores da educação pública e a sociedade como um todo. Além da implantação das atividades remotas, o controle da prática docente, a segurança alimentar dos estudantes, as políticas e práticas curriculares, o retorno das aulas presenciais, entre outras questões, constituíram-se em graves tensões que começaram a atravessar o mundo da educação e serem expostas em variados canais, formais ou informais, de comunicação.

Com base em nossa experiência e contato com redes e movimentos de profissionais da educação, principalmente com os que atuam na cidade do Rio de Janeiro, percebemos que, logo no início do emprego de atividades remotas, uma série de dúvidas e questionamentos passou a pairar entre aqueles que trabalham, militam e/ou pesquisam na EJA. Como primeiro problema, alertou-se sobre como atingir os educandos em distanciamento social se são esses os que mais passaram a sentir os impactos socioeconômicos da pandemia. Passadas as primeiras semanas e tendo como horizonte um período mais longo do que se esperava de distanciamento, muitas escolas e educadores iniciaram um processo de aproximação virtual com seus educandos. Conforme relatado ao longo do artigo, no entanto, logo se viu que esse contato seria mais complexo e incerto do que se poderia supor. Em razão disso e das políticas 
educacionais que já são anunciadas para o período posterior à pandemia, vimos a necessidade de depurar melhor nossas impressões e inquietações sobre todo esse processo, além de refletir com mais profundidade sobre as exigências que a crise nos trouxe.

A partir dessa conjuntura fomos levados, então, a analisar a real dimensão e abrangência desses impactos e a problematizar as decisões educacionais, principalmente as que se referem às atividades remotas e às políticas curriculares, os discursos que as balizam e os encaminhamentos a serem dados. Não são outros, portanto, os propósitos desse texto. Circunscrito ao atual momento de enfrentamento da pandemia, ou seja, aos acontecimentos que, no Brasil, se deram a partir de março de 2020, o objeto de estudo aqui apresentado refere-se à situação experimentada pelo país como um todo, mas toma como referência, para algumas de suas análises, fatos ocorridos no estado do Rio de Janeiro.

Nesse sentido, e cientes da inconclusiva tarefa de examinar fenômenos em pleno acontecimento, nossas reflexões iniciam-se a partir da análise de alguns dados disponibilizados por diferentes institutos de pesquisa, relativos aos principais efeitos da pandemia na vida dos trabalhadores. Como muitos deles encontram-se como estudantes da Educação Básica a EJA acabou por sentir, também, as consequências da crise. Em função disso, e encarada como uma modalidade da educação que sempre enfrentou adversidades, sua trajetória é, em seguida, brevemente revisitada com o intuito de contextualizar seus atuais desafios. Na seção seguinte, são tecidas considerações a respeito das atividades remotas, instituídas em muitas realidades educacionais, e suas repercussões entre educandos jovens, adultos e idosos. Por fim, a condição pós-pandemia é articulada à discussão para que se possa analisar as dificuldades e ameaças que já se impunham às especificidades curriculares da EJA e que tendem, no momento, a recrudescer. Com esse objetivo, são examinados documentos curriculares oficiais que produzem impactos diretos e indiretos na EJA, como a Base Nacional Comum Curricular (BNCC), e textos legais produzidos pelos órgãos públicos de ensino do estado de São Paulo e do município do Rio de Janeiro.

\section{Trabalhadores educandos em um mundo pandêmico}

A luta pelo reconhecimento da EJA como uma modalidade da Educação Básica sempre se pautou nas características de seu público, isto é, dos sujeitos que se configuram em seus potenciais educandos. Se seus traços essenciais se referem à faixa etária e às fases da vida humana, a eles agregam-se outras especificidades que ajudam a compreender, inclusive, os motivos que levaram à própria existência da modalidade e à luta por sua valorização.

Em razão disso, o debate em torno das identidades dos sujeitos educandos da EJA consiste em ponto central das reflexões sobre a modalidade, tanto no que se refere ao desenho e à implantação de políticas públicas, quanto no que diz respeito ao trabalho pedagógico a ser desenvolvido (CIAVATTA; RUMMERT, 2010; PAIVA, 2011; SALES; FISCHMAN, 2019). Por isso a necessidade de sempre se indagar sobre quem são, o que fazem, em que territórios vivem, que experiências de vida carregam e que lugar ocupam na sociedade de classes. Nesse sentido, concordamos que é preciso aprofundar o debate sobre as marcas 
identitárias desses sujeitos, principalmente as relacionadas a questões de gênero, de classe, de origem regional e étnico-raciais, dentre outras.

No entanto, compreendemos que a condição de classe social, invariavelmente articulada e potencializada por um ou mais desses aspectos identitários ${ }^{1}$, constitui a razão que, historicamente, leva a maioria dessas pessoas a não conseguir acesso ou a abandonar a escola durante a infância ou a adolescência. Tal condição, em geral, tem conduzido muitos desses sujeitos, precocemente, ao mundo do trabalho e à consequente necessidade de abandono prematuro da escola ou de mudança de turno/modalidade, uma vez que adolescentes e jovens que trabalham e frequentam a escola regularmente na idade considerada adequada recebem pouca atenção e apoio das escolas em que estudam (FRANZOI et al., 2019). Outros fatores interferem nesse afastamento da escola diurna de crianças e adolescentes, mas a inserção no mundo do trabalho é um dos principais motivos, posto que representa um imperativo ao qual muitos não conseguem escapar².

Justamente essa condição de classe e de trabalhador de baixa renda leva a maior parte dos educandos da EJA a situar-se entre a população mais vulnerável aos efeitos da pandemia da covid-19, sentindo tanto os impactos relacionados à doença em si e ao seu tratamento, quanto as consequências econômicas advindas da necessidade de distanciamento social. Desde março de 2020, portanto, muitos desses jovens, adultos e idosos que cursam a Educação Básica encontram-se em precária situação de sobrevivência e, muito provavelmente, com poucas perspectivas de retorno aos estudos.

$\mathrm{Na}$ disseminação da doença as disparidades aparecem, por exemplo, quando se analisa a taxa de letalidade, isto é, o número total de óbitos em relação ao número total de casos. Estudo realizado com base em informações obtidas em diferentes municípios brasileiros, no mês de maio, (BATISTA et al., 2020) examinou os dados de aproximadamente 30 mil pacientes com casos confirmados e encerrados (com óbito ou recuperação) de covid-19 e verificou a influência de fatores socioeconômicos na progressão da doença. Ao analisar a taxa de letalidade considerando variáveis socioeconômicas a pesquisa aponta, por exemplo, forte relação desse indicador com o nível de escolaridade e com a cor ou raça do paciente.

A partir do levantamento realizado, pode-se dizer que o nível de escolaridade tem alta determinação no desfecho da doença. Enquanto o óbito foi registrado entre $71,3 \%$ dos pacientes sem escolaridade, entre os que possuíam ensino superior não chegaram a $23 \%$ aqueles que faleceram. Verificou-se, ainda, que conforme o nível de escolaridade aumenta a taxa de letalidade diminui, o que significa dizer que as chances de sobrevivência dos pacientes dependem, em grande medida, do acesso à escolarização. Para os autores do estudo (BATISTA et al., 2020, p. 5), "[esse] efeito pode ser resultado de diferenças de renda, que geram disparidades no acesso aos serviços básicos sanitários e de saúde", além das disparidades na garantia do próprio direito à educação.

Quando os dados de escolaridade são agregados às informações relativas à raça/cor dos pacientes, o quadro apontado pelo mesmo estudo acaba por indicar outra perversa constatação: a taxa de letalidade da covid-19 é maior entre pessoas pardas e pretas quando comparada à verificada em pessoas brancas, em todas as faixas de escolaridade. De acordo com a pesquisa, o número de óbitos em pacientes pretos e pardos sem escolaridade foi quase 
quatro vezes maior do que o verificado em brancos com nível superior ( $76 \%$ contra $19,6 \%$, respectivamente). Em uma sociedade cujo racismo estrutural encontra-se enraizado, a pandemia acaba por expor, ainda mais, as injustiças sociais sofridas pelos afrodescendentes brasileiros, grupo que por conta exatamente dessas injustiças integra, majoritariamente, as classes de EJA como estudantes. Nesse aspecto da letalidade, portanto, são claras as desigualdades no que se refere aos trabalhadores mais destituídos de direitos, justamente aqueles que compõem o público potencial da EJA e seus próprios educandos.

A exacerbação das desigualdades poderia ter sido evitada se às classes populares não tivesse sido negado um direito essencial durante a pandemia: o direito à quarentena, isto é, ao distanciamento social digno e garantido pelo Estado. No entanto, mesmo que os esforços do poder público procurassem o atendimento a esse direito, o que não ocorreu de fato, as condições materiais de vida dos trabalhadores mais pobres seria um sério obstáculo a ser suplantado. Ficar em casa em quarentena pressupõe o acesso a moradia digna, por exemplo. O problema é que moradia é outro direito social historicamente negado a boa parte dos trabalhadores, principalmente aqueles que vivem em áreas urbanas, com destaque para as grandes metrópoles. Residências super povoadas, construções precárias, situação de rua, favelas e bairros populares com pouco ou nenhum acesso a saneamento básico conformam a realidade de imensos contingentes de brasileiros.

A quarentena, nesse sentido, acabou se tornando mais um privilégio circunscrito a certos bairros das metrópoles e cidades médias, relegando às periferias e favelas situações alarmantes frente ao combate à propagação e aos efeitos da covid-19. O caso das favelas da cidade do Rio de Janeiro, por exemplo, é emblemático. No mês de junho de 2020, segundo o Boletim Socioepiedemiológico da Covid-19 nas favelas, elaborado pela Fiocruz (2020a), a taxa de letalidade em bairros com alta concentração de favelas no município do Rio de Janeiro estava em 19,4\%. Isso quer dizer que de cada 100 pessoas diagnosticadas oficialmente com covid-19, quase 20 morreram. Na cidade, como um todo, essa taxa era de $11,7 \%$.

Embora a taxa de incidência da covid-19 nesses bairros seja oficialmente baixa em relação aos bairros sem favelas ou com baixa concentração de favelas, esse dado não deixa de ser alarmante. Ainda segundo a Fiocruz (2020a), essa baixa taxa de incidência deve-se a outro problema que demonstra as extremas desigualdades no enfrentamento à pandemia: a pequena quantidade de testes realizados nesses locais. Nos bairros onde vive a elite e estratos da classe média com maior renda, a testagem ocorre com mais frequência e, por isso, a taxa de incidência acaba sendo maior. Como indicadores da dispersão da doença e, portanto, essenciais no controle da pandemia, os testes também acabaram tornando-se privilégio das classes sociais mais abastadas, que puderam pagar por ele na rede privada de saúde. Já nos locais onde vive grande parte dos educandos da EJA, a ausência de testagem da população deixou à sorte a trajetória do novo coronavírus e a descoberto a real proporção do contágio entre seus moradores, gerando forte subnotificação de casos e falecimentos.

Um dado importante que atesta as graves consequências causadas pelo abandono de boa parte da população pelo poder público refere-se ao número de óbitos ocorridos em domicílio. Segundo a Fiocruz (2020b), a cidade do Rio de Janeiro registrou, nos meses de abril e maio 
de 2020, um aumento expressivo de mortes ocorridas nas residências em relação aos mesmos meses de anos anteriores. Foram $95 \%$ a mais de óbitos em domicílio, "o que revela não só a saturação da capacidade de hospitais, mas falhas graves de diagnóstico e tratamento oportuno de pessoas nas unidades básicas de saúde, bem como a desassistência de pessoas que sequer tiveram acesso aos serviços de saúde" (Nota Técnica da Fiocruz, 2020b, p. 1). Com isso, é bastante provável que muitos trabalhadores de baixa renda tenham morrido em suas casas sem nem mesmo terem procurado hospitais de referência, tanto para tratamento da covid-19 quanto para outras doenças.

No que se refere ao mundo do trabalho, a pandemia determinou marcas indeléveis em boa parte dos trabalhadores. Na primeira semana de agosto de 2020, a taxa de desocupação no Brasil alcançava 13,3\%, com uma alta de aproximadamente três pontos percentuais em relação ao início de maio ${ }^{3}$. Dados da PNAD Covid-19 (IBGE, 2020c) indicavam que, em julho de 2020, 23\% das pessoas sem Educação Básica completa não procuraram trabalho por conta da pandemia ou por falta de trabalho na localidade onde vivem. Novamente, é bastante provável que muitos alunos da EJA se encontrem nessas situações, ou seja, estão desocupados e com poucas chances de procurar trabalho. Enquanto isso, outra grande parcela de trabalhadores, principalmente os jovens, lançou-se às ruas na tentativa de gerar renda aumentando, assim, o risco de contaminação de seus corpos e de suas famílias.

Para aqueles que tinham alguma ocupação antes da pandemia, a PNAD Covid-19 aponta o quanto determinadas categorias sofreram mais que outras. Dados do mês de junho de 2020 indicam que os trabalhadores domésticos representavam 40,4\% do total de 8,3 milhões de pessoas afastadas do trabalho devido ao distanciamento social, dos quais $26,8 \%$ encontravam-se em situação de informalidade. Vale lembrar que, ainda segundo a PNAD, muitos desses trabalhadores afastados deixaram de ser remunerados. Outros dois setores foram, também, duramente atingidos e registraram queda na remuneração dos trabalhadores. De acordo com o Dieese $(2020)^{4}, 38 \%$ dos trabalhadores do setor de serviços e $25,4 \%$ do comércio tiveram suspensão de contrato ou redução de jornada e de salário. Importante mencionar que as categorias e setores citados estão entre as que mais empregam educandos da EJA das áreas urbanas, sendo a de trabalhadores domésticos marcada pela presença maciça de mulheres negras (PINHEIRO et al., 2019).

Vê-se, então, que a situação problemática do período anterior à pandemia agrava-se de maneira intensa e acirra as tensões que já atingiam o mundo do trabalho. Em análise sobre os impactos da crise sanitária na classe trabalhadora, Antunes (2020) lembra que, em 2019, $40 \%$ dos trabalhadores brasileiros encontravam-se na informalidade, sendo mais de 5 milhões sujeitos à condição de uberização do trabalho. Tratando ainda da "enormidade do desemprego e da crescente massa subutilizada, terceirizada, intermitente e precarizada em praticamente todos os espaços de trabalho" (Antunes, 2020, p. 8), o autor chama a atenção para a magnitude da tragédia na periferia mundial com a pandemia. O que por ele é denominado de capital pandêmico, isto é, a "simultaneidade e imbricação trágica entre sistema de metabolismo antissocial do capital, crise estrutural e explosão do coronavírus" (ANTUNES, 2020, p. 18), possui evidente traço discriminatório em relação aos trabalhadores e coloca-os diante de um verdadeiro fogo cruzado entre a luta pela sobrevivência e a 
contaminação, ambas com risco potencial de empurrá-los, ainda mais, para situações extremas de vulnerabilidade.

Nesse cenário, com inquietantes efeitos entre os trabalhadores, a EJA também se vê impactada. Com soluções pouco adequadas às suas especificidades, as decisões políticas de enfrentamento da crise no meio educacional acabam por posicioná-la em um estado de invisibilidade. Tal fato não é totalmente novo na trajetória da modalidade, conforme já indicamos, mas no atual contexto é acrescentada à sua história um dos momentos mais graves de riscos ao seu papel de garantidora do direito à educação das classes subalternizadas.

\section{Uma modalidade educativa de luta e em luta}

A história da Educação de Jovens e Adultos, no Brasil, como política pública consiste num processo bastante atual datando, de forma mais expressiva, de meados do século XX e o seu desenvolvimento, como materialidade educacional e curricular, apresenta momentos muito díspares de avanços e recuos. Ainda como política educacional é marcada pelo pontual e o emergencial, o que lhe confere aspectos de fragilidade e descontinuidade em sua oferta, tanto em termos nacionais como locais (HADDAD; DI PIERRO, 2000). Não cabe, na perspectiva desse artigo, realizar uma longa retrospectiva histórica, mas consideramos que, para problematizar os desafios colocados para a EJA no tempo presente, é necessário introduzir, como referência inicial, as Diretrizes Curriculares Nacionais para a Educação de Jovens e Adultos (DCNEJA) (BRASIL, 2000), documento curricular promulgado há exatos vinte anos e marco fundamental de mudança de concepção acerca da modalidade.

A Constituição de 1988 (BRASIL, 2016) indica, em vários de seus artigos, a garantia de políticas públicas para os sujeitos não escolarizados ou subescolarizados e oferece o aporte regulatório dessa oferta, possibilitando o desenvolvimento da EJA como uma modalidade da educação básica, o que lhe proporciona status e exigências legais para o reconhecimento das especificidades que jovens, adultos e idosos aportam em seus processos formativos no âmbito escolar.

De forma específica as DCNEJA, como produto da Constituição de 1988 (BRASIL, 2016) e da Lei de Diretrizes e Base da Educação Nacional (LDB), de 1996 (BRASIL, 1996), institui que a oferta nas etapas do Ensino Fundamental e Médio na modalidade EJA deve ocorrer em um modelo pedagógico próprio, onde os "princípios de equidade, diferença e proporcionalidade na apropriação e contextualização das diretrizes curriculares nacionais" (BRASIL, 2000, p. 1) são garantidos e validados. Dessa forma, a perspectiva curricular da EJA na oferta e na estrutura dos componentes curriculares pode, pela primeira vez na história das políticas públicas educacionais no país, dialogar centralmente com muitas das características de seus sujeitos educandos.

A importância histórica desse documento, como epicentro das lutas que o campo da EJA vinha promovendo desde o início da Nova República (1985), é primordial. Com sua promulgação acompanhamos uma progressiva ampliação da oferta em redes públicas municipais, estaduais e federal, sem perder de vista que tal oferta materializou- se mais como 
programas de governos do que como política de Estado, principalmente no âmbito da esfera federal de atuação (HADDAD; DI PIERRO, 2000). O debate em que se situa essa premissa deve considerar que, em muitas circunstâncias, tais programas reduziam-se a períodos datados de aplicação, eram desenvolvidos por educadores e professores fora do âmbito do serviço público - inseridos, portanto, em lógicas de precarização do trabalho docente - e, principalmente, configuravam-se em ações apartadas da possibilidade de continuidade da trajetória escolar dos educandos numa mesma etapa ou em etapas seguintes.

Outro elemento importante nesse debate é destacado por Fávero (2011) ao identificar as instâncias em que o acesso à EJA foi materializado e implementado. $\mathrm{O}$ autor indica que o fortalecimento da oferta vai se desenvolver de forma mais expressiva nas políticas promovidas pelas redes estaduais e municipais, que buscam ampliar respostas à crescente pressão da demanda local, do que aquelas promovidas pelo governo federal, já que este pulveriza o investimento em diferentes ações - os programas - e as atrela, como apêndices, a outras políticas sociais de combate à pobreza. Dessa forma, a esfera federal acaba por não assegurar processos estáveis de escolarização na perspectiva de atendimento a todas as etapas da Educação Básica. Nessa dimensão do debate é importante destacar o pacto federativo que, com a LDB de 1996 (BRASIL, 1996), institui determinadas obrigações aos distintos entes federados, ficando estados e municípios com a obrigatoriedade de oferta da Educação Básica, incluindo a oferta da modalidade da Educação de Jovens e Adultos, desobrigando, relativamente, uma oferta mais sistemática de políticas educacionais para a Educação Básica pela esfera federal.

A capilaridade da EJA nas redes municipais e estaduais deve ser, ainda, cotejada com uma reflexão fulcral quando identificamos o perfil dos sujeitos inseridos na modalidade. Fávero (2011) afirma que a oferta por essas redes tende a se estabelecer como uma política pública universal que insere o atendimento a jovens e adultos nas estruturas da escola regular o que gera, em um primeiro momento, um envolvimento mais intenso com as tradições curriculares escolares (ARROYO, 2005) e um diálogo muito tímido com as especificidades pedagógicas dos sujeitos da EJA sedimentadas nas DCNEJA. Por isso, em um movimento consequente, o autor entende que a EJA nas escolas tende a se tornar um lugar de ajuste ou correção dos entraves acarretados pela escolarização de crianças e adolescentes das classes populares. Assim, os processos de retenção, evasão e fracasso escolar que acompanham, de forma significativa, algumas dinâmicas de ampliação da escolarização no país encontrariam, na EJA, a possiblidade de adequação ou superação das barreiras nas trajetórias educacionais de seus sujeitos.

Em função disso, pode-se considerar que a EJA tem experienciado, nas últimas décadas, uma dinâmica de inserção cada vez mais significativa de jovens em suas turmas e escolas. Autores que estudam o fenômeno (DAYRELL, 2003; CARRANO, 2007) afirmam que esse processo deve ser entendido no âmbito dos elementos da cultura escolar e de seus modos de funcionamento, que contribuem - sem perder de vista que a escolarização é um fenômeno complexo e que apresenta muitas dinâmicas de causalidade para experiências de fracasso ou sucesso escolar - para que jovens com trajetórias escolares prolongadas sejam, muitas vezes 
prematuramente, inseridos na modalidade, conformando um processo de "juvenilização" de seu público.

Outro elemento que merece destaque é o reconhecimento de que as dinâmicas de "juvenilização" na modalidade têm sido acompanhadas por processos de descenso no quantitativo de matrículas e no atendimento a esse público, principalmente após os anos de $2010^{5}$. Quando mobilizamos os dados da Pnad de 2019 (IBGE, 2020b) é possível vislumbrar o tamanho dos desafios postos para a modalidade. Esse levantamento, por exemplo, indica a taxa de analfabetismo no patamar de 6,6\%, o que representa, em números absolutos, o contingente bastante significativo de 11 milhões de brasileiros com 15 anos ou mais nessa condição. Outro dado importante obtido pelo Pnad 2019, e já citado na introdução desse artigo, mostra que mais da metade de nossa população com mais de 25 anos de idade não possui o Ensino Médio completo, o que significa um grande número de pessoas que, pela condição de baixa escolaridade, configura-se em sujeitos demandantes da EJA. Importante destacar, no entanto, que tais números apresentam configurações díspares se considerarmos questões relacionadas à cor, à raça ou às regiões do país.

Conclui-se, assim, que a EJA vive, atualmente, um dos seus períodos históricos mais controversos, pois carrega um forte movimento de fechamento de turmas e matrículas, não consegue atender a demanda e encontra-se fragilizada em termos do sentido universal e escolar de sua oferta (NICODEMOS, 2019). Buscando trazer os elementos estruturais e históricos desse quadro, Nicodemos (2019) afirma ser esse período caracterizado por uma tendência de invisibilidade da EJA nas políticas educacionais e, ancorado no aporte teórico crítico que analisa as mudanças regulatórias pós-2016, adverte que a modalidade atravessa um processo de desescolarização, assim definido (NICODEMOS, 2019, p. 28):

[...] desescolarização da oferta na modalidade é um processo onde o atendimento a esse público dar-se-á fora da escola, ao contrário do que até então tínhamos concebido e garantido legalmente para jovens e adultos não escolarizados ou subescolarizados. Isso quer dizer que, na esteira dos processos de responsabilização e privatização da escola pública, a modalidade tende a ficar reduzida a duas ações prioritárias, qual seja: a Educação à Distância e a política de certificação.

O contexto onde tais processos históricos e educacionais desenrolam-se caracteriza-se pelo avanço e pela sedimentação de uma perspectiva ultraneoliberal e conservadora de sociedade, com severas consequências no modelo de escola pública a ser ofertado (FREITAS, 2012). Segundo essas propostas, o sistema educacional público brasileiro deve se ajustar a um padrão que consolida alterações em sua estrutura de oferta e sua lógica de funcionamento. A materialidade dessa tendência tem se dado através de inúmeras contrarreformas ${ }^{6}$ que procuram identificar e agir sobre a alegada ausência de qualidade da escola pública e, consequentemente, estabelecer alterações estruturais que têm, na privatização e na fragilização do sistema público universal de ensino, seus principais elementos (FREITAS, 2012). Quando situamos a EJA nessa tendência, podemos destacar duas contrarreformas específicas que atingem, em muito, a modalidade, principalmente em 
seus aspectos de oferta e permanência: a Lei no 13.415/2017 (BRASIL, 2017a), que estabelece a reforma do Ensino Médio, e o Decreto n 9.057/2017 (BRASIL, 2017b), que dimensiona a função e o caráter da Educação à Distância $(\mathrm{EaD})$ no âmbito da Educação Básica.

O conteúdo do Decreto n. 9.057/2017 (Brasil, 2017b) é bastante inquietante, já que nele há a indicação de que a EJA pode ser ofertada de forma exclusiva através da Educação à Distância (EaD). Com isso, podemos situá-lo na perspectiva do processo de desescolarização da oferta da modalidade alertando, ainda, para um elemento intrigante: a inexistência, no corpo do decreto, de regulamentação mais precisa sobre as formas de organização curricular da EaD na Educação Básica e, de forma mais específica, na EJA. Desse modo, o texto configura-se como uma legislação encurtada, em que questões sobre carga horária e modelos de oferta e material didático, dentre outras, não são apresentadas possibilitando, dessa maneira, ofertas aligeiradas e fragilizadas da modalidade pelas redes públicas de ensino.

Em relação à reforma do Ensino Médio, fica clara a tendência regulatória que reposiciona a EJA no lugar de desescolarização, já que o texto indica, mais explicitamente, a EaD como possibilidade formativa para a modalidade. Em relação ao Ensino Médio regular, o documento apresenta muitas indicações legais de inovação curricular, como a ampliação de carga horária e a construção dos itinerários formativos, por exemplo. No entanto, nenhum desses elementos, em nenhum momento, é referenciado ou indicado, de forma específica, para a EJA. Mais do que isso, o documento desconsidera totalmente as especificidades que os sujeitos dessa modalidade trazem e atravessam para a conclusão do Ensino Médio, como conjugar carga horária letiva com carga horária laboral. Além disso, as indicações para a modalidade presentes no art. $4^{\circ}$, inciso VI, fazem referência a "cursos realizados por meio de educação a distância ou educação presencial mediada por tecnologias" (BRASIL, 2017b) vislumbrando, claramente, o acanhamento ou a negação dos princípios curriculares das DCNEJA. Sendo assim, o texto aposta num currículo que, em sua essência, estrutura a precarização e a fragilidade pedagógica, tanto no uso da EaD como na educação presencial mediada por tecnologias.

Com isso é possível vislumbrar, então, que esse modelo de reforma se consubstanciará em um processo de ampliação da dualidade da educação brasileira, ou seja, uma oferta de Ensino Médio para a EJA reduzida como experiência presencial e outra oferta, mais robusta e com real potencial de acesso ao Ensino Superior, para a juventude que carrega trajetórias escolares mais padronizadas e estáveis.

Situando a Educação de Jovens e Adultos no quadro de sua desescolarização torna-se importante, ainda, citar duas outras políticas públicas de educação que ganharam muita expressividade no pós-2016. A primeira é o fortalecimento da política de certificação na Educação de Jovens e Adultos em âmbito federal, que tem no desenvolvimento do Exame Nacional de Certificação de Competências de Jovens e Adultos (Encceja) seu principal elemento de indução e que, após 2017, quando a prerrogativa de certificação do Ensino Médio deixa de estar no escopo do Enem (Exame Nacional do Ensino Médio), ganha expressividade numérica nunca antes experimentada. 
Destaca-se, ainda, que tais números de inscrição no Encceja resultaram de uma ação de propaganda massiva pelo governo federal tendo o exame ampliado, progressivamente, o número de inscritos. Segundo os dados disponibilizados nas Sinopses Estatísticas do ENCCEJA, divulgado pelo Instituto Nacional de Estudos e Pesquisas Educacionais Anísio Teixeira - Inep (Inep, 2019a), houve pouco mais de 1 milhão e meio de candidatos, em 2017, e mais de 2 milhões de inscritos, em 2019. Nesse mesmo ano, as matrículas da Educação de Jovens e Adultos alcançaram, em todo o país, pouco mais de 3 milhões e 200 mil (INEP, 2019b). Enxerga-se, assim, uma prevalência das possibilidades de oferta de certificação em detrimento do fortalecimento das ofertas presenciais para a modalidade que vêm, na última década, diminuindo progressivamente. Para efeito de indicar os limites desse tipo de política de certificação, com base nos dados disponibilizados pelo INEP (2019a), nos três anos posteriores a 2016, mesmo com números expressivos de inscrição o número de abstenções nos dias das provas apresentou-se em torno de $50 \%$ a $60 \%$, sendo que somente em torno de $20 \%$ dos que fizeram as provas conseguiram, de forma plena, a certificação, seja no Ensino Médio, seja no Ensino Fundamental.

Por fim, indicamos o lugar da Educação de Jovens e Adultos na Base Nacional Comum Curricular - BNCC (BRASIL, 2018a) como um dos mais significativos emblemas de invisibilidade que a modalidade atravessa marcada, ainda, por ações de desresponsabilização do Estado na sua oferta. Em tal documento não existe referência pormenorizada à Educação de Jovens e Adultos, bem como a outras modalidades da Educação Básica, estruturando uma proposta curricular que fixa, como horizonte, a organização do trabalho pedagógico nas escolas numa lógica de estreitamento curricular (FREITAS, 2012) buscando, em sua implementação, a construção de mecanismos radicais de padronização e testagem na Educação Básica.

Por estruturar-se em objetos do conhecimento, que nada mais são do que uma listagem simplificada de conteúdos, a BNCC (Brasil, 2018a) atua impondo restrições às opções do professor na seleção dos conteúdos e de sua amplitude e, ainda, na construção de hierarquias entre as disciplinas: as que serão priorizadas nos processos de testagens e aquelas que passam a ser consideradas disciplinas secundárias. Isso ocorre pois o centro dos processos de ensino e aprendizagem incide no bom desempenho na testagem dos conteúdos e na construção de ranqueamento entre as escolas e as redes, e não nos procedimentos efetivos e significativos de ensino e aprendizagem. E tais regimes de estreitamento curricular impostos pela BNCC mesmo considerando o fato de que a modalidade é invisível no documento - indica uma total incompatibilidade de seus pressupostos políticos e curriculares com aqueles previstos para a modalidade nas DCNEJA (BRASIL, 2000) o que anuncia ser o presente, mais do que nunca, o lugar da luta e da reafirmação dos princípios políticos e curriculares na modalidade e, principalmente, de reafirmação dos pressupostos curriculares que a compõem e que foram, ao longo das últimas décadas, lugar de resistência da EJA como direito para os milhões de brasileiros e brasileiras demandantes de escolarização e de escola. 


\section{EJA e atividades remotas: sobre incompatibilidades e desigualdades}

Se relacionarmos as mudanças regulatórias ao contexto da pandemia, temos um quadro bastante delicado e preocupante no que se refere às políticas de currículo para a Educação de Jovens e Adultos. Com o isolamento social e a suspensão das aulas presenciais é conferido ao ensino remoto, ou ao seu simulacro, a solução para muitas das questões que precisam ser equacionadas nesse momento, sejam aquelas relativas à necessidade de manutenção de vínculos entre a escola e os educandos, sejam aquelas pertinentes aos processos de formação e certificação escolar. Legalmente, o ensino remoto é amparado pelo Parecer CNE/CP 5/2020 (BRASIL, 2020, p. 8) que recomenda, excepcionalmente, "a adoção de atividades pedagógicas não presenciais a serem desenvolvidas com os estudantes enquanto persistirem restrições sanitárias para presença completa dos estudantes nos ambientes escolares". O texto do Conselho Nacional de Educação ainda esclarece que as atividades podem ser mediadas por tecnologias digitais de informação e comunicação.

Consideramos que tais ações têm impactado de forma incisiva nos modelos de escolarização vivenciados por docentes e discentes e que, na esfera da EJA, têm anunciado contornos de reedição dos mecanismos de exclusão escolar já vivenciados por esse público em suas trajetórias escolares, em função de dois aspectos. O primeiro refere-se ao acesso à tecnologia de informação para que as atividades remotas possam ser desenvolvidas de forma plena. O segundo aspecto reside no modelo pedagógico do ensino remoto, que implica em domínio de técnicas, níveis de letramento digital e alfabético e espaço habitacional com estrutura adequada, entre outras condições igualmente distantes da realidade de muitos discentes e docentes.

No que se refere ao trabalho docente, é importante destacar que o processo de didatização dos conteúdos de ensino é muito complexo, sedimentando-se e modificando-se a partir de fatores como as práticas docentes e as tradições curriculares, bem como os saberes da experiência e das disciplinas de referência - enfim, um processo amplo sobre o qual os educadores se debruçam cotidianamente. Trata-se de um procedimento singular, estruturado por trabalhadores docentes licenciados para essa tarefa, construído em um espaço presencial próprio e seguindo regras específicas da cultura escolar. Repentinamente, toda essa complexidade é desconsiderada e muitas comunidades escolares são inseridas, de forma aligeirada e abrupta, sem formação específica e sem experiência prévia, em processos tecnológicos de interação humana e pedagógica à distância, em um experimento social sem precedentes na história recente da educação escolar. As problemáticas consequências desse processo seriam sentidas, inevitavelmente, em pouco tempo.

Muitas redes públicas de ensino iniciaram o desenvolvimento de atividades remotas em momentos distintos e de diferentes maneiras com algumas, inclusive, considerando tais atividades como carga horária letiva. Esse é o caso, por exemplo, da rede estadual do Rio de Janeiro que passou a regular ${ }^{7}$ essas ações e exigir de seus docentes o lançamento de conteúdos escolares em plataformas digitais de educação remota e de seus gestores o acompanhamento desse processo, incluindo o acesso dos alunos às salas de aula virtuais. A decisão da Secretaria Estadual de Educação do Rio de Janeiro (SEEDUC) abrangeu diferentes níveis e 
modalidades de ensino, incluindo a EJA e, após um semestre letivo de aulas remotas, já se pode verificar os resultados desse processo e seus impactos no agravamento das desigualdades educacionais, em âmbito geral e no interior da própria rede estadual de ensino.

Dados sobre o ensino remoto produzidos pela própria Seeduc (Rio de Janeiro, 2020a) ${ }^{8}$ apontam para as dificuldades enfrentadas. Embora as informações relativas à EJA não estejam identificadas, é possível perceber a baixa interatividade geral, com $57,8 \%$ dos estudantes de toda a rede sem interação com a plataforma digital disponibilizada pela Seeduc. ${ }^{9}$ Os piores resultados, contudo, encontram-se nas sete Diretorias Regionais de Ensino situadas na região metropolitana, com destaque para a Metropolitana I, com 69,9\% de estudantes sem interação, a Metropolitana IV, com 69,1\%, e a Metropolitana VII, com 71,4\%. É importante salientar que essas diretorias abrangem a maior parte da Baixada Fluminense (Metropolitanas I e VII) e a parte norte da Zona Oeste do município do Rio de Janeiro (Metropolitana IV), justamente as áreas periféricas onde se encontra boa parte da população de mais baixa renda do estado.

Os resultados revelados por esse levantamento aproximam-se das informações obtidas pelo Fórum de Educação de Jovens e Adultos do estado do Rio de Janeiro (Fórum de EJA$\mathrm{RJ})^{10}$ sobre o acesso às atividades remotas pelos educandos da EJA de Ensino Médio dessa mesma rede. A consulta pública a docentes, realizada na primeira quinzena do mês de maio, teve como principais objetivos compreender como ocorria a inclusão da EJA nas atividades à distância e identificar as orientações curriculares indicadas pela secretaria de educação para esse período, além de possibilitar aos educadores um meio através do qual pudessem expor suas impressões sobre o processo.

Segundo o dossiê produzido com os resultados da pesquisa (Fórum de EJA-RJ, 2020a), o questionário foi respondido por 155 docentes de praticamente todas as diretorias regionais, com maior participação dos professores que atuam na Região Metropolitana. Quando perguntados sobre o acesso dos educandos às salas de aula virtuais de suas turmas, 66,5\% dos professores afirmaram que menos de $20 \%$ de seus alunos acessavam a plataforma. Sobre a frequência da conexão, no entanto, $76,8 \%$ dos profissionais asseguraram que não havia regularidade na interação. Como o levantamento foi realizado em maio, acreditamos que o quadro pode ter se tornado mais grave com o passar dos meses em função da piora da crise sanitária e seu consequente impacto socioeconômico.

A partir desses números, é importante identificar algumas possíveis razões para a baixa adesão dos estudantes da EJA à educação remota emergencial. Além dos já ressaltados impactos econômicos que muitos educandos enfrentam, o que os impede de priorizar os estudos nesse momento, é fundamental aprofundarmos as questões relacionadas ao acesso às tecnologias de informação e comunicação. Para tanto, voltamos a aspectos já apontados anteriormente com o propósito de analisá-los de forma mais detida.

É preciso sublinhar, de início, que situação econômica e acesso às tecnologias constituem, obviamente, aspectos interligados, uma vez que a realização das atividades remotas com algum conforto e qualidade técnica exige custos que ultrapassam as possibilidades financeiras de muitos educandos. Um dos requisitos para essa qualidade técnica, por exemplo, diz respeito ao dispositivo através do qual são acessadas as plataformas 
educacionais, onde boa parte das atividades pedagógicas se desenvolvem nesse momento. Dados da Pnad Contínua de 2018 (IBGE, 2020a) mostram que, apesar de a internet estar presente em $79 \%$ dos domicílios brasileiros, há grande diferença na relação entre o aparelho usado para o acesso e a renda média per capita dos domicílios. O telefone móvel celular é o dispositivo mais usado nos lares com rendimentos médios mensais equivalentes a 1.765 reais, enquanto o microcomputador é mais utilizado naqueles cuja renda média é de 2.569 reais, ou seja, quanto menor a renda, maior o uso do telefone celular para as conexões com a internet. Além disso, a mesma pesquisa aponta, também, que a principal finalidade do acesso para 95,7\% dos usuários é o envio e recebimento de mensagens por aplicativos.

Podemos dizer, portanto, que entre os trabalhadores de baixa renda é o celular que os leva à internet e, basicamente, com o uso voltado para a comunicação. Outros usos mais relacionados à educação escolar, como leitura, pesquisa de conteúdo e acesso a vídeos educativos, entre outros, não costumam fazer parte de sua rotina. Isso pode ser explicado tanto por dificuldades técnicas, como a inexistência de internet estável e com boa velocidade na região em que vivem, quanto pelo alto custo de requisitos que garantam boas condições de navegabilidade, como a aquisição de planos de internet compatíveis com as demandas de uso e a obtenção de aparelho com boa capacidade de armazenamento de dados e para uso exclusivamente individual, isto é, sem compartilhamento com outros membros da família.

Além disso, para aqueles educandos que conseguem superar as impossibilidades financeiras e técnicas, a falta de interação presencial com educadores e colegas pode desestimular a realização das tarefas remotas e a continuidade dos estudos. Na EJA, o contato, o acolhimento e o apoio mútuo são essenciais para o prosseguimento e a conclusão dos níveis de ensino. Em função das muitas dificuldades enfrentadas quando se decide voltar a estudar, o envolvimento afetivo é fundamental para a permanência dos educandos na escola, algo observado por Santos (2003) através de sua pesquisa sobre os impactos da escolarização tardia em adultos das classes populares. A investigação revelou que, para a maioria dos entrevistados, os educadores mostraram-se aliados essenciais para que ultrapassassem as dificuldades com as quais se deparavam ao longo da trajetória escolar. Nas narrativas dos depoentes, esses profissionais apareciam "como figuras sempre atentas, carinhosas e dispostas a fazer a mediação entre o aluno e o conhecimento, respeitando seu ritmo e contribuindo para a superação de seus limites [...]" (SANTOS, 2003, p. 34), tornando-se, na verdade, principais motivadores e facilitadores desse processo.

Em função exatamente desse papel que exercem, muitos educadores buscaram o contato remoto com os educandos durante o distanciamento social com a intenção de mantê-los em conexão com a escola e ampará-los em suas dúvidas e incertezas diante da crise sanitária. Muitas escolas e redes de ensino optaram por esse caminho, como revelou outro levantamento realizado pelo Fórum de EJA-RJ (2020b) junto às redes municipais de ensino do estado do Rio de Janeiro. A pesquisa, também realizada nas primeiras duas semanas de maio, alcançou 17 municípios e contou com 175 educadores respondentes. Desses, 66,9\% disseram estar mantendo contato com seus alunos através de redes sociais com o intuito de preservar vínculos e disponibilizar materiais para estudo. Em seus depoimentos sobre a experiência que vivenciavam, os docentes também apontaram muitas dificuldades e 
indicaram as possíveis razões para a baixa adesão dos educandos, mesmo não sendo obrigatórias as atividades disponibilizadas na maioria das redes participantes da consulta: foram sinalizados problemas de ordem técnica, econômica e de domínio tanto das ferramentas digitais quanto do próprio processo de aprendizagem mais autônomo que o distanciamento requer.

Podemos afirmar, portanto, que as atividades remotas, de modo geral, têm se mostrado incompatíveis com a modalidade EJA. Por todos os motivos já expostos, aquelas pautadas na transmissão de tópicos de conteúdos de ensino e consideradas como carga horária letiva pouco conseguiram atender ao discurso de que garantiriam o direito dos educandos à aprendizagem. As especificidades da EJA não foram atendidas, seja pela falta de sensibilidade em relação ao momento de crise que todos viviam, seja pela incompreensão de que atividades escolares não mediadas por relações presenciais, realizadas em condições impróprias e através de aparelhos inadequados, poderiam ser mais desestimuladoras que garantidoras de direitos. Daí a razão para os significativos números de absenteísmo digital para fins educativos e o afastamento da interação remota com a escola pelos educandos da EJA.

\section{Políticas curriculares da EJA em contexto pós-pandemia: novas ameaças?}

Em função de todo esse panorama, consideramos necessária a indagação a respeito das consequências sobre a EJA quando a pandemia tiver sido controlada. Nossas dúvidas e inquietações justificam-se em razão dos desmontes direcionados à modalidade e já expostos na segunda seção desse artigo. Dessa forma, enxergamos que a implementação da educação remota pode contribuir para a transformação do modelo presencial, até então indicado pelas DCNEJA (BRASIL, 2000) como prioritário, por modelos de Educação à Distância nas redes públicas de educação.

Em relação à legislação que já regulamenta a $\mathrm{EaD}$ na modalidade temos, no Ensino Fundamental, o Decreto no 9.057/17 (BRASIL, 2017b) - também já aqui citado - que, de forma generalista e superficial, indica que a EJA pode ser inteiramente ofertada por Educação à Distância, sem regulamentar ou explicitar suas formas específicas de organização e oferta. Já na etapa do Ensino Médio, a Resolução no 3, de 21 de novembro de 2018 (BRASIL, 2018b), que atualiza as Diretrizes Curriculares Nacionais para o Ensino Médio, prescreve, em seu $5^{\circ}$ parágrafo (BRASIL, 2018b, p 10), que "[n]a modalidade de educação de jovens e adultos é possível oferecer até $80 \%$ (oitenta por cento) de sua carga horária à distância [...]". Nesse sentido, com o lastro legal garantido, apenas restaria a implantação de ações políticas que poderiam ter como principais referências as experiências de atividades remotas desenvolvidas durante o período de distanciamento social.

Estaria, então, no período pós-pandemia, a possiblidade de real rompimento com o direito à educação diversificada e presencial para os sujeitos da Educação de Jovens e Adultos? Essa possiblidade coloca-se no horizonte curricular, pois estamos considerando que atravessamos uma disputa de concepções de currículo através da legislação, onde caminhos 
do desmonte já se encontram regulamentados, mas ainda ancorados, contraditoriamente, em legislações anteriores também validadas e não revogadas. Nessa direção, acreditamos que estariam nas ações locais das redes estaduais e municipais a possiblidade de manutenção ou de rompimento com os princípios centrais que regulamentam a EJA, entendida como direito e como potencial possiblidade de formação emancipatória para os seus sujeitos.

Outro debate inserido no contexto pandêmico e que merece ser cotejado com o quadro de desescolarização que indicamos gira em torno da construção de novos Referenciais Curriculares para a Educação de Jovens e Adultos, na esteira do processo de implementação da BNCC nos estados e municípios.

À vista disso, como apontado anteriormente, destacamos que a BNCC confere à EJA um lugar de invisibilidade, juntamente como outros marcos regulatórios educacionais no período pós-2016. Mesmo considerando que tal documento coloca-se, na perspectiva de seus elaboradores, como uma base e que deveriam ser estruturados, posteriormente, os currículos locais, consideramos que pode incidir sobre a EJA, na construção curricular local, o apagamento das especificidades que os sujeitos jovens e adultos impõem aos seus processos formativos, como materiais didáticos e formação de professores. $\mathrm{O}$ mesmo poderia ocorrer com o desenvolvimento de políticas curriculares que abarcam as distintas ofertas de atendimento diferenciado como a educação para privados de liberdade, a educação do campo, a educação quilombola e indígena e a educação especial.

Portanto, ao delegar aos estados e municípios a elaboração pulverizada de seus referenciais curriculares, tendo como aporte somente a BNCC - um documento encurtado, carente de pressupostos epistemológicos e curriculares e constituído, tão somente, de uma listagem de conteúdos ou objetivos de aprendizagem - prevemos um grande retrocesso curricular para a modalidade e, mais do que isso, a inviabilidade de manutenção de muitos dos princípios político-curriculares presentes na DCNEJA (BRASIL, 2000).

Atravessamos um debate curricular, em termos nacionais, que não enfrenta os grandes problemas da educação, como os números expressivos de retenção e evasão, as disparidades salariais do magistério público e as precárias condições de infraestrutura que atravessam as redes públicas. Além disso, impõe-se um discurso curricular enviesado, que procura justificar a necessidade premente de implementação da BNCC como um elemento a garantir o direito de aprendizagem para os educandos, em uma perspectiva retórica assentada na defesa da equidade e de oportunidades iguais para todos. Na verdade, tal retórica encobre o não enfrentamento, por parte das políticas educacionais, dos complexos desafios enfrentados pela expansão da educação pública nos últimos cinquenta anos.

Considerando, ainda, que o período pós-pandemia já vem sendo apresentado, por gestores públicos de educação, como um espaço significativo e necessário de reorganização curricular, antevemos que novas políticas de currículo serão aceleradas ou sistematizadas, já que em quadro de crise e de desestabilização de determinadas tradições educacionais abremse brechas para a consolidação, através da regulamentação, de contrarreformas aprovadas nos últimos anos.

Nesse sentido, destaca-se o anúncio do governo do estado de São Paulo de que, em 2021, pretende implementar a Reforma do Ensino Médio, sendo o primeiro estado a cumprir a 
legislação aprovada em 2017, com validade para as escolas públicas e privadas. No documento organizativo da matriz curricular, denominado Currículo Paulista (SÃO PAULO, 2020), a Educação de Jovens e Adultos é mencionada somente em duas das 301 páginas, o que replica a principal característica que tem marcado o tratamento da modalidade nos marcos regulatórios educacionais no pós-2016. Dessa forma, tal documento não anuncia, de forma concreta, como se dará a oferta da EJA na etapa do Ensino Médio, a carga horária e itinerários formativos que venham a considerar suas especificidades.

Um aspecto central nesse debate consiste na ampliação da carga horária total que a Reforma do Ensino Médio passou a definir: 3.000 horas curriculares. A proposta do estado de São Paulo (SÃO PAULO, 2020) amplia essa carga horária para 3.150 horas nos três anos de formação da etapa. Como será possível, para o estudante de Ensino Médio da EJA, cursar essa carga horária somente no turno noturno, se levarmos em consideração que ele cumpre carga horária diurna de trabalho? Essas e outras questões, inerentes aos processos de escolarização do educando jovem e adulto, não são explicitadas no documento conferindo à modalidade, mais uma vez, um lugar de invisibilidade e de não reconhecimento de suas especificidades. Ademais, o aumento da carga horária mínima - incompatível de ser cumprida pelo aluno trabalhador - abre brechas para a oferta de parte ou da totalidade da carga horária em formato de Educação à Distância, como preconiza a Resolução no 3/2018, que atualiza as Diretrizes Curriculares Nacionais para o Ensino Médio (BRASIL, 2018b).

Aprofundando a reflexão sobre o desenvolvimento de políticas curriculares no contexto pandêmico e pós-pandêmico podemos destacar, ainda, o exemplo da Rede Municipal de Educação do Rio de Janeiro, que avança na implementação de sua nova proposta curricular, denominada Currículo Carioca 2020 (RIO DE JANEIRO, 2020b). Encaminhada para o Conselho Municipal de Educação, no final de 2019, a proposta foi aprovada em janeiro de 2020 e está sendo disponibilizada como subsídio para atividades remotas complementares não obrigatórias - em curso. Na página eletrônica da Multirio, ${ }^{11}$ foram disponibilizados os materiais pedagógicos de apoio aos professores e de complementação escolar para os alunos da rede, segmentados por ano de escolaridade incluindo, também, material específico para a Educação de Jovens e Adultos. Ao longo da apresentação dos referidos materiais indica-se que eles são alinhados ao Currículo Carioca 2020.

Buscando compreender os elementos usados nesse constructo curricular para a modalidade, bem como a forma em que se estabelece o diálogo entre o Currículo Carioca 2020 para a EJA e os materiais pedagógicos de complementação disponibilizados ${ }^{12}$, novamente divisamos um lugar de fragilidade da modalidade nos processos de construção de políticas de currículo. Na apresentação do Currículo Carioca $2020^{13}$ são disponibilizados, somente, os documentos curriculares para as etapas do Ensino Fundamental e Educação Infantil, de fato homologados em janeiro de 2020. Inexiste, dessa forma, referências à EJA e podemos supor que o material pedagógico de apoio para a modalidade foi construído com base em um vácuo curricular explicitado, quando se apresenta o referido material, na vaga premissa de que recursos de apoio pedagógico referentes aos conteúdos curriculares da EJA estariam disponíveis. 
No quadro de disputas sobre concepções curriculares que atravessamos, cabe-nos indagar: que seriam os “conteúdos curriculares da Educação de Jovens e Adultos” expressos na introdução do material? Não existe, também, referência mais específica aos documentos que serviram para a construção do material de complementação na modalidade. Cabe indagarmos, ainda, se a ausência da Educação de Jovens e Adultos no Currículo Carioca 2020 seria o anúncio de brechas indutoras para uma alteração no modelo de oferta presencial para modelos de EaD ou não presencial. Ou, simplesmente, mais uma consequência do não lugar da EJA nas políticas curriculares em curso no país.

Para efeito de conclusão desse item, vale destacar que nossas indagações sobre os caminhos e as bases das políticas de currículo para a EJA não partem de uma análise estável, principalmente na dimensão de sua materialidade concreta no tempo presente imediato. Consideramos, nesse esforço ensaístico, que vivemos um tempo instável e de grandes e rápidas transformações. Portanto, as questões e os exemplos colocadas podem ser redefinidores de processos de desescolarização da EJA, ou não, e este devir encontra-se em disputa.

\section{Considerações finais}

Vivemos um tempo de debates e embates complexos. Nossas pautas e questões urgentes no passado e em constante processo de luta e conquista nas duas últimas décadas fragilizamse. $\mathrm{O}$ contexto de desmonte das políticas públicas que vivenciamos recentemente tem trazido para a modalidade da Educação de Jovens e Adultos novos e perplexos desafios, onde a sua existência como escola, como política pública e como direito encontram-se realmente ameaçadas. Profundos processos de invisibilidade e desescolarização marcam a modalidade, atualmente, e se acirram no quadro de pandemia da covid-19, posicionando a modalidade em um local de fronteira, de disputa entre concepções de currículo e políticas educacionais. Essa experiência do lugar de disputa é inerente à histórica luta que a educação de adultos trabalhadores empreendeu ao longo do tempo e em diferentes contextos políticos no Brasil. A força da mobilização e de luta de muitos sujeitos coletivos é que forjou os avanços que a modalidade alcançou na redemocratização do país, quando materializou-se como expressão de políticas públicas e com garantia legal e orçamentária, em termos de oferta no âmbito federal, estadual e municipal.

O lugar fronteiriço que a EJA vai ocupando nas políticas educacionais forjadas com as contrarreformas e acirradas com a pandemia, ao mesmo tempo que nos causa estranhamento e preocupação, também anunciam um tempo da resistência necessária e urgente, com o qual se depara o sentido desse ensaio. Um tempo onde nos colocamos em organização, em mobilização e em produção intelectual na direção de revelar e problematizar o contexto político que a modalidade atravessa como ferramenta para que os diferentes sujeitos educadores, professores, gestores, intelectuais e legisladores - possam empreender, coletivamente, estratégias de visibilidade e garantia escolar para a modalidade. E que esse lugar da resistência estabeleça pontes com o que acumulamos historicamente, como a 
legislação de garantia de direitos, por exemplo, nas DCNEJA, ou ainda, e principalmente, com as experiências do chão da escola, na construção de currículos praticados.

Por fim, para seguir em frente, apoiamo-nos no aforismo de Antônio Gramsci: o velho mundo agoniza, um novo mundo tarda a nascer e, nesse claro-escuro, irrompem os monstros. Que não só os monstros surjam, mas também a resistência. E que através dela possamos disputar e garantir a EJA como direito para milhões de brasileiros que oferecem a dimensão da existência de muitas cores vivas nesse claro-escuro que ora atravessamos.

\section{Notas}

1. Não há como dissociar as identidades étnico-raciais e de gênero da condição de classe, por exemplo, quando falamos dos trabalhadores e trabalhadoras no Brasil. A própria composição dos educandos da EJA é marcada pela presença majoritária de mulheres negras trabalhadoras de baixa renda (Ribeiro; Catelli Junior; Haddad, 2015).

2. De acordo com a Pesquisa Nacional por Amostra de Domicílios - PNAD Contínua 2019, o abandono escolar acontece, sobretudo, na passagem do Ensino Fundamental para o Ensino Médio e a principal razão para essa situação é a necessidade de trabalhar (39\%) seguida da falta de interesse (29\%) (IBGE, 2020b).

3. Informações obtidas através do portal da Pesquisa Nacional por Amostra de Domicílios para o período da pandemia, a PNAD Covid-19, realizada mensalmente pelo IBGE. Disponível em: covid19.ibge.gov.br/pnad-covid.

4. O gráfico referente a esses números encontra-se na p. 11 (Dieese, 2020).

5. De acordo com dados do Censo Escolar da Educação Básica (INEP, 2019b), houve redução de 1 milhão de matrículas na EJA, entre 2010 e 2019, em todas as etapas de ensino e dependências administrativas. Tal redução recrudesceu o desequilíbrio entre oferta e demanda potencial no período, já que, em 2010, segundo o Censo Demográfico, havia aproximadamente 70 milhões de pessoas com 25 anos ou mais de idade sem a Educação Básica completa (Censo Demográfico 2010, 2011).

6. As contrarreformas são mobilizadas, nesse artigo, na perspectiva apontada por Ramos e Frigotto (2016). Para os autores, tais movimentos políticos, em geral ancorados na Lei n. 13.415/2017 (Brasil, 2017a), que trata da reforma do Ensino Médio, reeditam o retrocesso e o conservadorismo em termos de políticas públicas educacionais e, principalmente, fragilizam as legislações aprovadas em décadas anteriores no país, principalmente após 1988.

7. Documento CI SEEDUC/SUGEN SEI no 22, emitido pela Seeduc/RJ em 05 de abril de 2020.

8. O documento, intitulado Acompanhamento do Ensino Remoto, apresenta dados coletados entre 25/05 e 17/07/2020, a partir da observação de 923 colégios de Ensino Médio, que representam 49,5 \% das unidades da rede nessa etapa, e de 468 escolas de Ensino Fundamental, que representam 55,2\% do total para esse nível de ensino. Reconhecemos que tal levantamento está sendo realizado como expressão positiva de diagnóstico da rede e que tem uma natureza provisória, pois ainda estamos inseridos no contexto de desenvolvimento da educação remota no âmbito da rede.

9. O Google for Education consiste numa plataforma que engloba diversas ferramentas educacionais para escolas públicas e privadas do mundo e que ganhou grande destaque mundial no quadro de distanciamento social. Em 18 de março de 2020, a Seeduc/RJ firmou parceria com o Google para a utilização dessa plataforma de estudos, destinada a alunos e professores da rede, com o objetivo de possibilitar a manutenção de educação remota durante o período em que não houvesse aulas presenciais.

10. O Fórum de Educação de Jovens e Adultos do Estado do Rio de Janeiro (Fórum EJA/RJ) constitui um movimento social comprometido com a discussão, o fortalecimento e a proposição de caminhos para a EJA no estado do Rio de Janeiro articulando-se, em âmbito nacional, com o movimento dos Fóruns de EJA do Brasil.

11. A Empresa Municipal de Multimeios, vinculada à Secretaria Municipal de Educação da Prefeitura da cidade do Rio de Janeiro, cumpre a "missão de pesquisar linguagens e formatos, experimentar possibilidades tecnológicas em conteúdos curriculares, produzir recursos de aprendizagem, ampliar as formas de distribuição de produtos educativo-culturais e capacitar os profissionais da educação para a utilização das mídias em sala de aula." (http://multirio.rio.rj.gov.br/index.php/multirio/a-multirio). 
12. Os materiais de apoio estão disponíveis em http://multirio.rio.rj.gov.br/index.php/estude/material-de-complementacaoescolar. Acesso em: 24 ago. 2020.

13. O Currículo Carioca pode ser acessado no Portal Rio Educa, um espaço virtual onde materiais pedagógicos, reportagens e relatos de experiências sobre a educação municipal são disponibilizadas pela Secretaria Municipal de Educação do Rio de Janeiro ao público em geral. Disponível em: http://www.rio.rj.gov.br/web/rioeduca/exibeconteudo/ ?id=10885079. Acesso em: 26 ago. 2020.

\section{Referências}

ANTUNES, Ricardo. Coronavírus: o trabalho sob fogo cruzado. Rio de Janeiro: Boitempo Editorial, 2020. (Pandemia Capital)

ARROYO, Miguel A educação de jovens e adultos em tempo de exclusão. In: Construção coletiva: contribuições à educação de jovens e adultos. Brasília: UNESCO, MEC, RAAAB, 2005. p. 221-230 (Coleção educação para todos)

BATISTA, Amanda et al. Análise socioeconômica da taxa de letalidade da COVID-19 no Brasil. Nota técnica 11/2020. Rio de Janeiro: Núcleo de Operações e Inteligência em Saúde - NOIS/PUC-RJ, 2020. Disponível em: https://sites.google.com/view/nois-pucrio/publica\%C3\%A7\%C3\%B5es. Acesso em: 25 jul. 2020.

BRASIL. Constituição da República Federativa do Brasil de 1988. Brasília, DF, 2016. Disponível em http://www.planalto.gov.br/ccivil_03/Constituicao/Constituiçao.htm. Acesso em 10 de out. de 2020.

Diretrizes Nacionais para a Educação de Jovens e Adultos. Brasília: MEC, 2000. Disponível em: http://portal.mec.gov.br/cne/arquivos/pdf/PCB11_2000.pdf. Acesso em: 4 fev. 2019.

. Lei de Diretrizes e Bases da Educação Nacional. Lei número 9.394, Brasília, 20 de dezembro de 1996.

Lei $n^{\mathbf{0}}$ 13.415, de 16 de fevereiro de 2017. Altera as Leis nos 9.394, de 20 de dezembro de 1996 e institui a Política de Fomento à Implementação de Escolas de Ensino Médio em Tempo Integral. Brasília, fev. 2017a. Disponível em: 〈http://www.planalto.gov.br/ccivil_03/_ato2015-2018/2017/lei/L13415.htm>. Acesso em 10 de out. de 2020.

Decreto $\mathbf{n}^{\mathbf{0}}$ 9.057, de 25 de maio de 2017. Brasília: MEC/CNE, 2017b. Disponível em: http://www.planalto.gov.br/ccivil_03/_ato2015-2018/2017/decreto/d9057.htm. Acesso em: 30 ago. 2020.

Base Nacional Comum Curricular (BNCC). Brasília, 2018a. Disponível em: http://basenacionalcomum.mec.gov.br/abase/ Acesso em 10 de out. de 2020.

MEC/CNE/CEB. Resolução $\mathbf{n}^{\mathbf{0}}$ 3, de 21 de novembro de 2018. Brasília: MEC/CNE, 2018 b. Disponível em: http://www.in.gov.br/materia/-/asset_publisher/Kujrw0TZC2Mb/content/id/51281622. Acesso em: 20 ago. 2019.

Parecer CNE/CP No 5/2020. Brasília: MEC/CNE, 2020. Disponível em: http://portal.mec.gov.br/index.php?option=com_docman\&view=download\&alias=145011-pcp00520\&category_slug=marco-2020-pdf\&Itemid=30192. Acesso em: 15 out. 2020.

CARRANO, Paulo. Educação de Jovens e Adultos e juventude: o desafio de compreender os sentidos da presença desses alunos na escola da segunda chance. Revej@: Revista de Educação de Jovens e Adultos, Belo Horizonte, v. 1, n. 0, p. 55-67, 2007. Disponível em: http://bit.ly/2XNi03H. Acesso em: 22 nov. 2017.

CENSO DEMOGRÁFICO 2010: resultados da amostra: educação e deslocamento. In: IBGE. Sidra: sistema IBGE de recuperação automática. Rio de Janeiro, 2011. Disponível em: <https://sidra.ibge.gov.br/pesquisa/censo-demografico/demografico-2010/amostra-educacao-edeslocamento>. Acesso em: ago. 2020. 
CIAVATTA, Maria; RUMMERT, Sonia. As implicações políticas e pedagógicas do currículo na educação de jovens e adultos integrada à formação profissional. Educação e Sociedade. Campinas, v. 31, n. 111, p. 461480, abr.-jun. 2010. Disponível em http://www.cedes.unicamp.br. Acesso em: 21 abr. 2019.

DAYRELL, Juarez. O jovem como sujeito Social. Revista Brasileira de Educação, n. 24, set./dez, p. 40-52. Rio de Janeiro, 2003.

DIEESE. Departamento Intersindical de Estatísticas e Estudos Socioeconômicos. A covid-19 e os trabalhadores do Comércio. Estudos e Pesquisas, n. 94, jul. 2020. Disponível em: https://www.dieese.org.br/ estudosepesquisas/2020/estPesq94CovidComercio.html. Acesso em: 23 ago. 2020.

FÁVERO, Osmar. Políticas públicas de educação de jovens e adultos no Brasil. In: SOUZA, José dos Santos; SALES, Sandra Regina. (Orgs.) Educação de Jovens e Adultos: políticas e práticas educativas. Rio de Janeiro: NAU Editora, EDUR, 2011.

FIOCRUZ. Análise da frequência, incidência, mortalidade e letalidade por COVID-19 em favelas cariocas. Boletim Socioepiedemiológico da Covid-19 nas favelas, n. 1. Rio de Janeiro: Fiocruz, 2020a. Disponível em: https://portal.fiocruz.br/sites/portal.fiocruz.br/files/documentos/boletim_socioepidemiologicos_covid_nas _favelas_1.pdf. Acesso em: 13 jul. 2020.

FIOCRUZ. Óbitos desassistidos no Rio de Janeiro. Análise do excesso de mortalidade e impacto da Covid19. Nota técnica 11/2020 (Monitora Covid-19). Rio de Janeiro: Fiocruz, 2020b. Disponível em: https://bigdata-covid19.icict.fiocruz.br/nota_tecnica_11.pdf. 14 jul. 2020. Acesso em: 13 jul. 2020

FIOCRUZ. Boletim Socioepidemiológico da Covid-19 nas favelas. 2020c.

FÓRUM DE EJA-RJ. Dossiê sobre Consulta aos Professores/as da Rede Estadual do Rio de Janeiro sobre Educação RemotaDIEESE. Rio de Janeiro: Fórum EJA-RJ, 2020a. Disponível em: http://forumeja.org.br/rj/node/531. Acesso em: 17 ago. 2020.

FÓRUM DE EJA-RJ. Dossiê sobre Consulta aos Professores/as das Redes Municipais do Estado do Rio de Janeiro sobre Educação Remota. Rio de Janeiro: Fórum EJA-RJ, 2020b. Disponível em: http://forumeja.org.br/rj/node/529. Acesso em: 19 ago. 2020.

FRANZOI, N. L. et al. O estudante trabalhador na escola pública: um direito negado? Arquivos Analíticos de Políticas Educativas, 27(136). (2019). Disponível em: https://doi.org/10.14507/epaa.27.4068. Acesso em: 22 jul.2020.

FREITAS, L. Os reformadores empresariais da educação: da desmoralização do magistério à destruição do sistema público de educação. Educação e Sociedade, Campinas, v. 33, n.119, p. 379-404, abr.-jun. 2012.

HADDAD, Sérgio; DI PIERRO, Maria Clara. Escolarização de jovens e adultos. Revista Brasileira de Educação. n. 14, mai.jun.jul.ago, p. 108-130, 2000

IBGE. Pesquisa Nacional por Amostra de Domicílios Contínua. Acesso à Internet e à televisão e posse de telefone móvel celular para uso pessoal 2018. Rio de Janeiro: IBGE, 2020a. Disponível em: https://biblioteca.ibge.gov.br/visualizacao/livros/liv101705_informativo.pdf. Acesso em: 14 jul. 2020.

Pesquisa Nacional por Amostra de Domicílios Contínua. Educação 2019. Rio de Janeiro: IBGE, 2020b. Disponível em: https://biblioteca.ibge.gov.br/visualizacao/livros/liv101736_informativo.pdf. Acesso em: 23 jul. 2020.

Pnad Covid-19. Rio de Janeiro: 2020c. Disponível em: covid19.ibge.gov.br/pnad-covid. Acesso em: 27 ago. 2020.

INEP. Sinopses Estatísticas do Encceja. Brasília: INEP, 2019a. Disponível em http://portal.inep.gov.br/web/guest/sinopses-estatisticas-do-encceja Acesso em 10 de out. de 2020.

Censo escolar da Educação Básica. Brasília: INEP, 2019 b.

NICODEMOS, Alessandra. A Educação de Jovens e Adultos em contexto conservador e ultraneoliberal: caminhos do desmonte, caminhos da resistência. In: JULIÃO, Elionaldo Fernandes; RODRIGUES, Fabiana. 
(Orgs.). Reflexões Curriculares para a Educação de Jovens e Adultos nas prisões. 1ed. São Paulo: Paco Editorial, 2019.

PAIVA, Jane. Inclusão na Educação de Jovens e Adultos. Debates em Educação Científica e Tecnológica, v. 01, n. 1, p. 14-23, 2011. Disponível em: https://ojs.ifes.edu.br/index.php/dect/article/view/8. Acesso em: 22 jul. 2020.

PINHEIRO, Luana et al. Os desafios do passado no trabalho doméstico do século XXI: reflexões para o caso brasileiro a partir dos dados da Pnad contínua. Brasília: IPEA, 2019. (Texto para discussão 2528)

RAMOS, Marise; FRIGOTTO, Gaudêncio. Medida Provisória 746/2016: a contra-reforma do ensino médio do golpe de estado de 31 de agosto de 2016. Revista HISTEDBR [on-line], v. 16 n. 70, p. 30-48, dez. 2016.

RIBEIRO, Vera Masagão; CATELLI JUNIOR, Roberto; HADDAD, Sérgio (Orgs.). A avaliação da EJA no Brasil: insumos, processos, resultados. Brasília: Instituto Nacional de Estudos e Pesquisas Educacionais Anísio Teixeira, 2015. Disponível em: http://rbep.inep.gov.br/ojs3/index.php/relatos/article/view/4081. Acesso em: 23 jun. 2017.

RIO DE JANEIRO. Secretaria Estadual de Educação. Acompanhamento do período remoto. 2020a. (37 slides). Apresentação em Power Point.

RIO DE JANEIRO. Secretaria Municipal de Educação. Currículo Carioca. Rio de Janeiro, 2020b. Disponível em http://www.rio.rj.gov.br/web/sme/exibenoticias?id=10907097. Acesso em 10 de out. de 2020.

SALES, Sandra R.; FISCHMAN, Gustavo E. Promessas, políticas e interrogações sobre as identidades dos sujeitos da EJA. Currículo sem Fronteiras, v. 19, n. 3, p. 1131-1141, set./dez. 2019. Disponível em: https://www.curriculosemfronteiras.org/vol19iss3articles/sales-fischman.html. Acesso em: 22 jul. 2020.

SANTOS, Geovania L. dos. Quando adultos voltam para a escola: o delicado equilíbrio para obter êxito na tentativa de elevação da escolaridade. In: SOARES, Leôncio (Org.). Aprendendo com a diferença: estudos e pesquisas em educação de jovens e adultos. Belo Horizonte: Autêntica, 2003.

SÃO PAUlO. Currículo Paulista: Etapa do Ensino Médio. São Paulo, 2020. Disponível em https://efape.educacao.sp.gov.br/curriculopaulista/ensino-medio. Acesso em 10 de out. de 2020.

\section{Correspondência}

Alessandra Nicodemos: É Professora de Didática e Prática de Ensino de História da Faculdade de Educação da UFRJ. Pesquisadora do Laboratório de Investigação, Ensino e Extensão em Educação de Jovens e Adultos (LIEJA). Professora do Programa de Mestrado Profissional em Ensino de História (ProfHistória)/UFRJ.

E-mails: alenicodemos@yahoo.com.br

Enio Serra: É Professor de Didática e Prática de Ensino de Geografia da Faculdade de Educação da UFRJ. Coordenador e pesquisador do Laboratório de Investigação, Ensino e Extensão em Educação de Jovens e Adultos (LIEJA).

E-mail: enio.serra@gmail.com

Texto publicado em Currículo sem Fronteiras com autorização dos autores 